\title{
Carnets
}

Revue électronique d'études françaises de l'APEF

Première Série - 5 | 2013

Métamorphoses littéraires

\section{A arte da leitura e a excelência do comércio das musas: Gérard de Nerval e os poetas do século XVI}

Marta Kawano

\section{(2) OpenEdition}

Journals

Edição electrónica

URL: http://journals.openedition.org/carnets/8299

DOI: 10.4000/carnets.8299

ISSN: 1646-7698

Editora

APEF

Edição impressa

Data de publição: 1 Maio 2013

Paginação: 103-118

Refêrencia eletrónica

Marta Kawano, «A arte da leitura e a excelência do comércio das musas: Gérard de Nerval e os poetas do século XVI », Carnets [Online], Première Série - 5 | 2013, posto online no dia 23 junho 2018, consultado o 19 abril 2019. URL : http://journals.openedition.org/carnets/8299; DOI : 10.4000/ carnets.8299

\section{(c) (1) (8)}

Carnets est mis à disposition selon les termes de la licence Creative Commons - Atribution - Pas d'utilisation commerciale 4.0 International. 


\title{
A ARTE DA LEITURA E A EXCELÊNCIA DO COMÉRCIO DAS MUSAS \\ Gérard de Nerval e os poetas do século XVI
}

\author{
MARTA KAWANO \\ Universidade de São Paulo \\ marta.kawano@uol.com.br
}

\begin{abstract}
Resumo
O artigo busca refletir sobre as relações entre leitura e criação na obra de Gérard de Nerval a partir da recente reedição de uma antologia dos poetas do Século XVI realizada pelo autor em 1830 (Choix des poésies de Ronsard, Du Bellay, Baïf, Belleau, Du Bartas, Chassignet, Desportes, Régnier). Pelo projeto da antologia o poeta se engaja na batalha pelo Romantismo na França. A consideração de seu trabalho como compilador abre espaço para uma série de reflexões a respeito da porosidade de fronteiras no domínio literário (entre os gêneros, entre criação e crítica, memória e invenção literárias...). O modo como, na antologia de Nerval, essas fronteiras são transgredidas, permite-nos ainda colocar sua obra em diálogo com algumas formulações do pensamento romântico alemão.
\end{abstract}

\begin{abstract}
The present paper aims at an analysis on the relationship between reading and creating in Gérard de Nerval's work from his 1830's anthology of $16^{\text {th }}$ century poets (Choix des poésies de Ronsard, Du Bellay, Baïf, Belleau, Du Bartas, Chassignet, Desportes, Régnier), newly republished. The anthology plan engaged the poet on the battlefield for Romanticism in France. An account of his work as a compiler unfolds a series of analysis on the boundaries porosity within the literary realm (between the different genres, creation and criticism, memory and literary inventiveness...). The way by which these boundaries are transgressed, in Nerval's anthology, allows us still to place his work in close relation with some favourite topics of German romantic thought.
\end{abstract}

Palavras-chave: Gérard de Nerval, Romantismo, crítica literária, poesia francesa do século XVI. Keywords: Gérard de Nerval, Romanticism, literary criticism, French poetry of the $\mathrm{XVI}^{\text {th }}$ century. 
Quando, em La Bohême galante (1842), Gérard de Nerval retoma parte da "Introdução" à antologia dos poetas do século XVI realizada por ele em 1830 (Choix des poésies de Ronsard, Du Bellay, Baïf, Belleau, Du Bartas, Chassignet, Desportes, Régnier), ele a apresenta humoristicamente mediante uma comparação com o "sermão que o bom Sterne" acrescentava às aventuras macarrônicas de Tristram Shandy. Em seguida o poeta expressa o desejo de que "fragmentos" do estudo, com seu "air académique", despertem o interesse do leitor da época... (Nerval, 1993: 243). O Choix de Nerval constitui a matéria do primeiro tomo das CEuvres complètes do autor, sob a direção de Jean-Nicolas Illouz e a cargo da Classiques Garnier ${ }^{1}$. A reedição do Choix é um trabalho acadêmico rigoroso, mas por detrás de seu "air académique" o leitor encontrará ainda uma vigorosa interpretação da obra do poeta, pois o intuito desse primeiro tomo é mostrar que o trabalho de Nerval como antologista é uma obra de criação, em sentido forte. Na edição - realizada por Emmanuel Buron e Jean-Nicolas Illouz - a leitura detida e abalizada da letra se dá com vistas à compreensão do espírito, a consideração de cada detalhe nunca deixa de ser acompanhada de um olhar para o todo. E aqui se mostra o trabalho conjunto de dois hermeneutas.

O livro, que é fruto de uma dupla competência (nos estudos do século XVI e do século XIX), traz duas introduções, uma apresentação esclarecedora dos "Principes de la présente édition", textos de apresentação às partes dedicadas a cada um dos poetas e notas de rodapé nas quais esse duplo olhar está todo o tempo presente, numa dinâmica pela qual se procura dar testemunho "de la vie des œuvres dans le temps: de la renaissance dans le romantisme; des poètes du XVle siècle à Nerval; et de Nerval, aujourd'hui, pour l'avenir" (Nerval, 2011: 66). O propósito de "dar testemunho da vida das obras no tempo" e o modo como isso foi realizado na reedição suscita uma série de reflexões a respeito da obra de Nerval e do Romantismo, reflexões que se articularão aqui em torno da ideia de transgressão de limites do campo literário: a porosidade entre leitura e invenção, criação e crítica, assim como aquela existente entre passado, presente e futuro no processo de criação e interpretação literária.

Essas reflexões se originam na própria natureza do trabalho hermenêutico que resulta no livro, pois, neste caso, não se trata apenas de editar ou interpretar um texto conhecido do autor, mas de resgatar, como obra de criação, um trabalho de edição realizado pelo poeta, e de inseri-lo no conjunto de sua produção e no contexto mais amplo do Romantismo. Diríamos que, na raiz da possibilidade de se publicar hoje, como obra de Nerval, uma antologia realizada pelo poeta em 1830, encontra-se o que se pode denominar de metamorfose literária em dois planos. Num primeiro plano, o termo "metamorfose" serve

\footnotetext{
${ }^{1}$ No conjunto, a nova edição das $C$ Euvres complètes será composta de treze volumes, que serão publicados nos próximos anos.
} 
para designar o modo pelo qual, na obra obra de Nerval, a leitura se transforma em criação. Num segundo plano (complementar ao primeiro) veremos que o termo "metamorfose" pode designar o resultado do trabalho filológico realizado na reedição, pelo qual se inscreve o Choix de Nerval no conjunto da obra de criação do poeta. É pelo olhar crítico que se inventa (e o sentido desta invenção será elucidado mais adiante) e se recria uma obra de Nerval. Mas tal invenção só é possível porque, na reedição do Choix, a leitura da letra se orienta pelo espírito da obra nervaliana.

A leitura da letra guiada pelo espírito fará com que, ao final da leitura do livro, questionemo-nos sobre o sentido da palavra "todo" no que diz respeito à obra de Nerval e sejamos levados a compreender que, das Obras completas desse escritor, pode fazer parte o seu trabalho como compilateur. É o que nos mostra a edição, voltando-se para a produção nervaliana de 1830 (portanto anterior à escrita das obras que tornariam Nerval conhecido). Ora, em 1830, após ter publicado, pela "Bibliothèque choisie", um Choix de Poésies Allemandes, Nerval publica (na mesma coleção) o Choix de Poésies de Ronsard... Em ambos os casos podemos pensar que ele teria efetivamente escolhido publicar as coletâneas e que as marcas dessas escolhas estariam inscritas no próprio trabalho realizado pelo poeta.

Indo um pouco além, parece haver uma intenção comum aos dois projetos a que o poeta se dedica em 1830: o de promover a literatura romântica na França pela reintrodução de uma literatura de outra época (século XVI) e pela divulgação da literatura de outro país (a Alemanha). Tal constatação nos permitirá, ao longo de nosso percurso, apontar algumas afinidades entre o projeto nervaliano do Choix e certos aspectos do pensamento romântico, tal como se encontram nas obras de August e Friedrich Schlegel, e de Novalis. Nossa ênfase estará menos na localização de fontes (teóricas ou literárias) de posições e "práticas" nervalianas e mais (como dissemos) na sugestão de afinidades entre aspectos da obra do poeta e algumas formulações do pensamento romântico alemão, particularmente no que diz respeito à criação, à crítica literária e à leitura. Foi em grande medida o trabalho de reedição do Choix de Nerval - e o modo como ele ajuda a delinear de forma mais clara o lugar ocupado pelo escritor na perspectiva mais ampla do Romantismo - que nos abriu esse caminho de reflexões ${ }^{2}$.

Ao acompanharmos o trabalho de reedição do Choix de Nerval, compreenderemos a íntima relação que a leitura e a seleção dos poetas do século XVI estabelecem com a criação ulterior do poeta. E veremos também o quanto o Choix é uma escolha estratégica pela qual Gérard de Nerval se engaja na batalha pela renovação da literatura francesa.

\footnotetext{
2 Assim como nos fez também refletir sobre um diálogo possível entre o projeto nervaliano e algumas formulações de Jorge Luis Borges a respeito da leitura de obras literárias, que exploraremos adiante.
} 
O trabalho de reedição leva em conta, a cada passo da edição, o todo no qual estão inseridos os textos. O Choix de Nerval é posto constantemente em diálogo com os esforços de seus contemporâneos (e predecessores) na defesa do Romantismo (como Sainte-Beuve e Victor Hugo) e no ataque ao Classicismo do século XVII, que teria obliterado toda uma veia nacional e popular da literatura francesa cujo resgate, visto como crucial para sua renovação, exigia uma reconsideração da História. Tal reconsideração diz respeito à própria Escola de Ronsard, que foi contemplada de ângulos bastante diversos ao longo do tempo. Ela foi ofuscada pelo advento do Classicismo e depois, em 1820, por ele revalorizada. Foi acusada pelos românticos de ter submetido a literatura francesa à imitação da Antiguidade, para depois ser por eles reabilitada e vista como estratégica no resgate de uma literatura nacional. Todos os diferentes horizontes históricos nos quais se inscrevem os textos - o da poesia do século XVI e o de sua recepção em 1830 (assim como o do Classicismo) tornam-se claramente visíveis pelo trabalho de reedição.

Mas "saisir l'historicité plus profonde des œuvres" (Nerval, 2011: 66) - um dos propósitos dos editores - é também testemunhar a passagem do tempo na própria obra nervaliana e compreender retrospectivamente como ela foi fecundada pela leitura dos poetas do século XVI, para cujo "renascimento" Nerval contribuiu.

A edição dessa obra de leitura tem como ponto de partida a compreensão de que tal renascimento se dá, no caso de Nerval, e já em 1830, pelas mãos de um poeta - e enquanto poeta. E nisto seu Choix teria uma natureza bem diversa do Tableau historique et critique de la poésie et du théâtre au XVI siècle e das CEuvres Choisis de Ronsard, de Sainte-Beuve, publicados em 1828.

O constante vaivém entre dois momentos da produção nervaliana - o de sua inserção (em 1830) na batalha pelo Romantismo na França e o de sua criação ulterior; assim como o jogo entre os dois modos pelos quais se dá a criação nervaliana - pela leitura e pela escrita - é todo o tempo levado em conta. Aqui então compreendemos o quanto, na reedição do Choix de Nerval, a leitura minuciosa da letra se liga ao espírito, ou ao modo singular de ser da obra nervaliana. Ocorre que uma das características mais singulares dessa obra é precisamente a liberdade e a naturalidade com que o poeta se apropria da criação alheia: “Je suis l'autre' n'est pas seulement la devise pathétique de la folie de Nerval: bien avant cela, ce peut aussi être la dévise d'une écriture largement fondée sur l'emprunt et l'appropriation" (Nerval, 2011: 28) .

\footnotetext{
${ }^{3} \mathrm{Na}$ prática da escrita nervaliana são frequentes as apropriações criativas da produção alheia. É o que ocorre (para nos atermos a um exemplo) com a novela intitulada "Jemmy", uma das narrativas reunidas por Nerval em Les Filles du feu. Ao final da novela, lêem-se as seguintes palavras: "Imité de l'allemand". Trata-se, na verdade, de uma tradução bastante livre (o original é de autoria de um escritor austríaco) que, inserida no conjunto de narrativas e poemas de Les Filles du feu, transforma-se numa (re) criação nervaliana. É ainda em Les Filles du $\mathrm{Feu}$ - na carta-prefácio que abre o volume de ("A Alexandre Dumas") que se encontra a célebre frase de Nerval
} 
$\mathrm{Na}$ obra de Nerval, a leitura engendra a criação, e os editores foram sensíveis, em todas as suas singularidades, aos ressouvenirs das leituras dos poetas do XVI que se podem "ouvir" ao fundo da invention nervaliana. Com isto, "la philologie la plus scrupuleuse invente", por sua vez, "une œuvre de Nerval, c'est à dire, au sens étymologique, la découvre" (Nerval, 2011: 66). Inventa-a porque se recorda todo o tempo da obra nervaliana posterior e leva em conta a apropriação orgânica de obras alheias que a caracteriza. $E$ descobre-a retrospectivamente, anacronicamente. Mas nisso também constitui uma leitura fiel à obra nervaliana, ou a um dos "nœuds névralgiques de l'imaginaire nervalien" (Nerval, 2011: 13): uma temporalidade toda feita de retornos, de ecos e reminiscências, ritmada por um "ballet des heures" que liga horas e idades num "seul moment". Essa visão do tempo ${ }^{4}$ (e da História) pode estar em consonância com a tese formulada por Nerval em sua "Introduction", na qual (citando Friedrich Schlegel) ele aponta a necessidade de voltar "à la littérature française des temps anciens" como forma de garantir o movimento progressivo da poesia francesa. ${ }^{5}$ Mas, segundo Jean-Nicolas Illouz, a própria ideia de renascimento estaria ligada, em Nerval, "à un désir de renaissance qui réassurerait la continuité rompue des âges" (Nerval, 2011: 13). Ora, essa configuração do tempo no imaginário nervaliano permite pensar que não há solução de continuidade entre o antologista de 1830 e o autor Gérard de Nerval das décadas seguintes, assim como não haveria solução de continuidade entre o Nerval leitor e o Nerval escritor.

Quanto ao Nerval compilador, sabemos o quanto sua obra de criação é fruto da atividade de antologista de si mesmo, pois boa parte dela é composta por um trabalho de deslocamento pelo qual os mesmos textos, inseridos em outros contextos e publicados em outros momentos, podem se metamorfosear e adquirir novos significados. Nerval elevaria "la pratique de la compilation au niveau d'une poétique" (Nerval, 2011: 27). Ora, antologizar, em 1830, os poetas do século XVI - assim como fazer uma antologia, no mesmo ano, dos poetas alemães - é operar tal deslocamento também num âmbito mais amplo, pois visa mover algumas linhas de força da literatura francesa do período.

Mas fazer os mesmos textos dizerem algo diverso pelo simples gesto de inseri-los em outros contextos não deixa de ser uma arte, ou, ao menos, uma técnica da "arte detida e rudimentar da leitura: a técnica do anacronismo deliberado e das atribuições errôneas", que foi praticada por "Pierre Menard, autor do Quixote", personagem do célebre conto de Jorge

- "Inventer au fond c'est se ressouvenir" - frase que pode ser lida como uma síntese da estreita relação existente, no processo de criação nervaliano, entre criação e leitura, entre memória literária e imaginação criadora.

${ }_{5}^{4}$ Adiante consideraremos com mais detalhe a questão da temporalidade cíclica na obra de Nerval.

${ }^{5}$ Adiante apontaremos outras afinidades entre a proposta do Choix de Nerval (e do trabalho realizado em sua reedição) e formulações de Friedrich Schlegel. 
Luis Borges ${ }^{6}$ : "Esta técnica de aplicação infinita nos insta a percorrer a Odisseia como se fosse posterior à Eneida" (Borges, 2007a: 80). As palavras de Borges serviriam para descrever a "arte da leitura" tão peculiarmente nervaliana, mas também servem para comentar o modo como essa obra de Nerval foi lida por Jean-Nicolas Illouz e Emmanuel Buron: trata-se de numa leitura orientada por um olhar anacrônico (mas por isso mesmo revelador) e que realiza uma atribuição aparentemente errônea. Precisamente por essas razões ela nos permite ir mais fundo no processo de criação nervaliano.

Mas é o Borges do ensaio intitulado "Kafka e seus precursores" que pode nos ajudar a compreender mais detalhadamente a arte detida da leitura dos editores do Choix de Nerval.

O ensaio de Borges é muito conhecido pelo paradoxo no qual se funda (e que não é senão uma nova formulação do anacronismo acima apontado): a ideia de que "cada escritor cria seus precursores. Seu trabalho modifica nossa concepção do passado assim como há de modificar o futuro" (Borges, 2007b: 130). Evidentemente, todos os ecos apontados pelos editores entre os poetas do século XVI e a obra posterior de Nerval nos permitem compreender o quanto esses poetas-precursores são criados por Nerval (por um gesto deliberado, e nisso diferindo do que ocorre com Kafka, cujos precursores são encontrados por Borges em sua Biblioteca). Mas tão importante quanto a tese paradoxal de Borges é o modo como ele a formula:

Se não me engano, as peças heterogêneas que enumerei se parecem com Kafka; se não me engano, nem todas se parecem entre si. Este último fato é mais significativo. Em cada um desses textos reside a idiossincrasia de Kafka, em grau menor ou maior; mas se Kafka não tivesse escrito, não a perceberíamos, ou seja, ela não existiria (Borges, 2007b: 130).

No início do ensaio, Borges crê ter reconhecido a "voz" ou os "hábitos" de Kafka nos escritores que enumera, e que seriam então vistos como prefigurações da obra kafkiana.

Detivemo-nos nas considerações de Borges pois a conhecida a argúcia desse escritor para captar (por uma aproximação muito concreta entre os textos) as "idiossincrasias", os "gestos" e "hábitos" dos escritores nos ajuda a sublinhar o aspecto mais notável do trabalho de Emmanuel Buron e de Jean-Nicolas Illouz, sobre o qual pretendemos refletir um pouco. Se podemos ler com uma lente nervaliana os poetas escolhidos por Nerval, se eles nos parecem retrospetivamente nervalianos (e cada um à sua maneira), se,

\footnotetext{
${ }^{6}$ Conto ao qual Emmanuel Buron faz discreta alusão em sua "Introdução".
} 
pelo processo da leitura, eles se tornam nervalianos, é porque os editores nos mostram, por uma leitura prática, muito concreta e minuciosa, a consonância entre os textos. Vejamos.

A "Introdução" de Nerval ao Choix - texto analítico e argumentativo - é marcada por uma dupla posição. A uma acusação, na qual Gérard (seguindo Sainte-Beuve) aponta a Escola de Ronsard como a responsável pela submissão da literatura francesa à imitação da Antiguidade, segue-se uma defesa de Ronsard, na qual o autor "change subrepticement d'objet, pour s'intéresser moins à la doctrine affichée de la Pléiade (qu'il condamne), qu'aux œuvres elles-mêmes, qu'il admire" (Nerval, 2011: 10). Há então uma primeira abordagem, marcada (nas palavras do próprio Nerval) por um "retour d'étude et d'investigation" (Nerval, 2011: 73), pelo olhar de um historiador que se engaja na batalha romântica; e uma outra, a de uma "lecture plus particulière", que pode "vous reconcilier" (Nerval, 2011: 99) com os poemas, e na qual se desvela, como aponta Jean-Nicolas Illouz:

une pratique de la langue française qui excède le parti pris de l'imitation de l'Antiquité [...] On ajoutera que cette pensée de la langue, parce qu'elle se découvre au contact des poèmes (et non pas seulement dans un geste de l'historien) est inséparable d'une attention aux modes de son énonciation, qui la singularisent en l'incarnant dans une voix parlante à travers les siècles. Cette attention à la voix conduira Nerval, on l'a dit, à retrouver, au-délà d'un certain phrasé chantant du vers renaissant, les vieilles ballades françaises et les chansons populaires (Nerval, 2011: 10-12).

É pelo contato direto com os poemas ("une lecture particulière") que Nerval buscará fazer renascer, em 1830, os poetas da Escola de Ronsard (esperando que eles frutifiquem neste outro tempo). E será certamente pelo contato direto com os poemas do passado que estes deixarão sua marca na produção nervaliana das décadas seguintes.

Nerval estaria aqui criando alguns de seus precursores, pois reconheceria nesses poetas sua própria "voz" (ou suas diferentes "vozes"), suas "idiossincrasias" e seus próprios "hábitos", ainda em germe.

Os editores captam as ações pelas quais a leitura se torna criação, ações que são nomeadas pelo próprio Nerval, que tinha a intenção de "retirer quelque fruit" do estudo dos poetas anteriores ao século XVII (Nerval, 2011: 73), que teria sido "impressionné" "malgréIur" pela forma e pelo estilo desses poetas, e que os teria tomado [Ronsard] como "modèle". Ao descrever sua própria criação, Nerval chega a conferir um novo sentido (positivo) ao neologismo de Malherbe: "en ce temps, je ronsardisais" (Nerval, 1993: 264).

Se enfatizamos a ideia de ação no modo como Nerval lê os poetas é no intuito de apontar, na obra nervaliana, uma maneira muito peculiar de apropriação dos poetas do passado: uma imitação que se orienta por um princípio vivificador da leitura das obras 
alheias. E podemos aqui abrir parênteses para sugerir que essa visão (ou essa prática) da imitação em Nerval guarda afinidades com uma concepção orgânica da obra literária (e da própria história literária) tal como se encontra no pensamento romântico alemão: não seria um mero acaso o fato de a "Introdução" de Nerval ao Choix estar repleta de metáforas orgânicas $^{7}$, que estão em grande medida articuladas em torno de um trecho de Friedrich Schlegel citado pelo escritor.

A visão orgânica da obra literária é uma constante no Romantismo alemão. Podemos encontrá-la, por exemplo, na oposição estabelecida por August Schlegel (em suas Conferências sobre a arte dramática e literatura) entre forma orgânica e forma mecânica, que se desdobra ainda na oposição entre imitação mecânica (própria do Classicismo francês, segundo Schlegel) e imitação orgânica. A lógica organicista está presente ainda em diversos fragmentos de Novalis, como o fragmento 41 de "Poesia", que parece curiosamente (e anacronicamente) adequado para comentar o modo pelo qual Nerval retomou a poesia do século XVI:

Há uma imitação sintomática e uma genética. Esta última é a única vivente [...] Essa faculdade de despertar verdadeiramente em si uma individualidade alheia - não meramente enganar através de uma imitação superficial - é ainda totalmente desconhecida - e repousa sobre uma sumamente prodigiosa penetração e mímica espiritual. O artista faz de si tudo aquilo que vê e quer ser" (Novalis, 2001: 123).

O modo de ser do Choix de Nerval (de maneira mais geral, a dinâmica pela qual, em sua obra, a leitura se metamorfoseia em criação) teria, ao nosso ver, profundas afinidades com muitos pontos do projeto dos românticos alemães, pelo caráter vivo e ativo da leitura e pela incorporação transformadora da criação alheia. ${ }^{8}$ Como forma de sugerir mais uma vez tal afinidade, tomemos outro fragmento de Novalis $^{9}$ como mote para prosseguirmos na compreensão do trabalho realizado por Nerval em seu Choix: "Como pode um ser humano ter sentido para algo se ele não tem o germe dentro de si. O que devo entender tem de desenvolver-se em mim organicamente - e aquilo que pareço apreender é apenas alimento, incitamento ao organismo" (Novalis, 2001: 45).

Nerval teria sido como que incitado pela leitura de Du Bartas, um dos poetas do século XVI resgatados por seu Choix, e em cuja obra ele parece ter se reconhecido, por nela perceber algo que teria "em germe dentro de si". Consideremos mais detidamente como isso se daria.

\footnotetext{
${ }^{7}$ Adiante veremos que estas metáforas são apontadas pelos editores como um leitmotiv do Choix de Nerval.

${ }^{8}$ Além da ideia de uma crítica criadora e produtiva e da visão progressiva - schlegeliana - da história literária a que nos referimos acima, e à qual retomaremos um pouco adiante.

9 Trata-se do fragmento 19 de "Observações entremescladas".
} 
O caráter ativo, criativo e transformador da leitura nervaliana aparece de forma patente nos versos de "Tarascon", soneto que Nerval reproduz numa carta a Victor Loubens de 1841 (durante uma de suas crises de loucura):

\section{Ô seigneur du Bartas! suis-je de ce lignage}

Moi qui soude mon vers à ton vers d'autrefois...

A escrita é marcada aqui por uma adesão (souder) ao verso de Du Bartas, e também por uma filiação (lignage), em 1841, ao verso d'autrefois. Ora, o que a reedição do Choix mostra em detalhes é que esse processo de "soldagem" já teria se iniciado uma década antes, quando Nerval, ao elaborar sua antologia, escreve no exemplar de Du Bartas da Bibliothèque Royale: "Ce livre a été lu tout entier par Gérard en mil huit cent trente" (Nerval, 2011: 300).

Há aqui um jogo temporal cujo sentido convém considerarmos de maneira mais aprofundada antes de contemplarmos os meandros da releitura nervaliana da poesia de Du Bartas, tais como apontados pelos editores do Choix.

Note-se - pelos versos de "Tarascon" e pela inscrição feita no volume da Bibliothèque Royale - que a relação de Nerval com a poesia de Du Bartas se dá de forma muito peculiar no que diz respeito ao tempo: é como se o "verso d'autrefois", com o qual ele toma contato em 1830, permanecesse em estado de reelaboração (ou nele se "desenvolvesse organicamente", para retomarmos os termos de Novalis) por um longo tempo até que, como criador (em 1841), Nerval se filiasse voluntariamente à lignage de Du Bartas pela escrita de seus próprios versos. Temos aqui uma temporalidade interna e circular que embaralharia os momentos da leitura e da criação, e aproximaria imaginação criadora e memória literária: "Inventer au fond c'est se ressouvenir". É pelo trabalho da memória que se realiza a metamorfose poética e a transformação do alheio em próprio. Mas deve-se ressaltar que, neste caso, a metamorfose parece iniciar-se no momento da leitura, momento em que Nerval se reconhece nos versos de Du Bartas ao quais retornará mais tarde.

Em estudo sobre "Goethe como crítico", Ernst Robert Curtius aponta algo muito semelhante no processo de criação do escritor alemão. O ponto de partida da leitura do crítico é um verso no qual se percebe a reunião dos tempos que ocorre pelo processo da criação literária (segundo a lógica orgânica, que ocupa um lugar central no pensamento de Goethe): “'Laß den Anfang mit dem ende sich in eins zusammenziehen' [Deixai que início e fim num só se reúnam]. Segundo Curtius, "esse verso exprime o que há de mais peculiar no sentimento goethiano da vida e remete os leitores de Goethe a outras passagens que 
expressam o mesmo" (Curtius, 1984: 55). Em seguida, o crítico cita um trecho do escritor ${ }^{10}$ que permitiria compreendermos mais profundamente o sentido da metamorfose literária goethiana, pela qual início e fim se reúnem:

certos grandes motivos, lendas, antiquíssimas tradições históricas gravaram-se tão profundamente na alma que eu as mantive vivas e atuantes em meu íntimo por quarenta ou cinquenta anos; parecia-me ser meu bem mais precioso ver essas valiosas imagens frequentemente renovadas em minha imaginação, já que, na verdade, elas se metamorfoseiam repetidamente sem contudo perderem sua essência, amadurecendo até uma forma mais pura, até uma representação mais definitiva (Curtius, 1984: 55).

A visão cíclica do tempo, como apontamos no início deste texto, é uma constante na obra de Nerval. Ela se encontra, por exemplo, no soneto "Artémis" ("Ballet des heures"), que figura o retorno ao passado pelos movimentos do ponteiro de um relógio: "La Treizième revient... C'est encor la première": a décima-terceira hora que é de novo a primeira.... ${ }^{11} . A$ temporalidade cíclica estaria ainda no fundamento da visão nervaliana do processo criativo e na aproximação entre ressouvenir et invention, pois, em Nerval, a criação literária é, em grande medida, uma reelaboração - uma metamorfose - daquilo que se encontrou na leitura de obras alheias. É o que se pode perceber na retomada nervaliana de Du Bartas, poeta cujo livro teria sido lido "tout entier" por Gérard em 1830, e que ele teria escolhido para fazer parte se seu Choix.

O alcance profundo dessa escolha é revelado pelo trabalho de reedição que aponta para uma vertente da leitura nervaliana dos poetas do século XVI que não seria marcada pela "grâce chantante d'une poésie valorisée pour se qualités de simplicité" e de "transparence" (Nerval, 2011: 299), mas pela língua "moins polie" e pela poesia "plus hermétique" de Du Bartas. Gérard teria ainda encontrado em Du Bartas um sincretismo entre cristianismo e paganismo mitológico (que marcará muitos momentos de sua produção ulterior). O próprio modo como o poeta rearranja os textos é significativo. Um exemplo disso é a criação de uma sequência narrativa entre três poemas, sequência "qui fait passer d'un monde en harmonie avec Dieu à une rupture avec cette harmonie, puis à une de reprise de

\footnotetext{
${ }^{10}$ A tradução do trecho de Curtius, assim como da passagem de Goethe citada pelo crítico (extraída de Allegemeine Naturwissenschaft) foi realizada por Magali Moura.

${ }^{11}$ A imagem do relógio cujo ponteiro se desacerta está presente ainda na Introdução de Nerval ao Fausto de Goethe ("Faust de Goethe suivi du second Faust": "Il semble, pour nous servir d'une comparaison triviale, mais qui exprime parfaitement cette bizarre évolution, que l'horloge éternelle, retardée par un doigt invisible, et fixée de nouveau à un certain jour passé depuis longtemps, va se détraquer comme un mouvement dont la chaîne est brisée, et marquer ensuite un siècle pour chaque heure" (Nerval, 1989: 509). Curiosamente, a comparação presente na passagem (caracterizada pelo autor como "trivial"), encontra-se num trecho de sua própria lavra: "la chaîne était brisée et marquait les heures pour des minutes" ("A Alexandre Dumas”, in Nerval, 1993: 451).
} 
contact ambiguë" (Nerval, 2011: 302). Tal reordenação parece obedecer a uma temática e a uma lógica muito singularmente nervalianas.

O indício fornecido pela carta de 1841 - que, além de "Tarascon", trazia uma versão do soneto "Antéros" e um primeiro esboço do futuro "Le Christ aux Oliviers" - é o ponto de partida para os editores aproximarem de forma mais estreita este último poema de "Le sacrifice d'Abraham", de Du Bartas. Então acompanhamos de perto os passos da leitura de Nerval e o modo como seu verso, "comme versus, comme retour, comme schème rhytmique mémoriel" (Nerval, 2011: 18) segue os rastros do verso de Du Bartas, já, de início, pelo retorno da rima "abîme/victime", que, insistente em "Le sacrifice d'Abraham", estará presente em: "Frères, je vous trompais: Abîme! Abîme! Abîme!/ Le dieu manque à l'autel, où je suis la victime..." do segundo terceto "Le Christ aux Oliviers", soneto que seria "tout entier motivé par cet écho sonore" (Nerval, 2011: 309). O poema de Nerval "se solda" ao poema de Du Bartas também no que diz respeito ao modo de enunciação: há em ambos (com algumas diferenças) um quadro épico no qual ocorre a "inserção de desenvolvimentos dramáticos e líricos" (Nerval, 2011: 310). Do ponto de vista temático, os editores apontam para a relação de prefiguração que se estabelece, na teologia cristã, entre o sacrifício de Isaac e o de Cristo (temas, respectivamente, nos poemas de Du Bartas e de Nerval). E então a relação temática e formal entre os poemas (cujos "nós intertextuais" são apontados em detalhes pelos editores) pode ser compreendida como uma relação de prefiguração. Se considerarmos de outro ângulo a relação entre os poemas, veremos que:

c'est Du Bartas qui 'renaît' en Nerval, qui hante sa voix, - comme si le vers pouvait suspendre 'l'ordre du temps', en faisant résonner dans la langue une immense mémoire intertextuelle, tout entière 'concentrée' dans le moment, hors du temps, de sa profération (Nerval, 2011: 18-19).

A língua e a voz de Du Bartas diferem do "style primitif et verdissant" que Nerval, como poeta-arqueólogo, pode desvelar auscultando os poemas de Ronsard (assim como "Avril", de Belleau) (Nerval, 2011: 10). É a "lecture particulière" que lhe permite ouvir, nos versos de Ronsard, "un certain phrasé chantant de la langue française, beaucoup plus ancien" (Nerval, 2011: 10). E vê-se então, claramente, o espírito progressivo pelo qual se retoma o passado, pois recuperar a "naïveté et la fraicheur" da poesia de Ronsard é nela ouvir os ecos do estilo "primitivo e verdissant", de um "air plus ancien" que deve trazer frescor (segundo Nerval, leitor de Friedrich Schlegel) para a poesia francesa em 1830. A retomada se liga ainda à tentativa nervaliana de recuperar esse fraseado em sua criação posterior. 
O modo como Nerval rearranja os poemas de Ronsard em seu Choix também traz as marcas do trabalho realizado por um compilador-poeta. A divisão dos poemas em "Odes", "Discursos" e "Sonetos" obedeceria a uma visão dos gêneros característica de 1830 e, neste sentido, seria uma espécie de "Préface a Cromwell em ato" (Nerval, 2011: 107), pois a divisão entre "Odes" e "Discursos" corresponderia à distinção hugoliana entre "poesia lírica" e "poesia épica". Diversos deslocamentos, montagens e découpages realizados por Gérard parecem trazer para o primeiro plano certos temas caros ao nosso poeta. Isso ocorre tanto pelo reordenamento de poemas - como na criação do pequeno ciclo sobre a flor e a primavera (na parte dedicada às "Odes" de Ronsard), quanto pela prioridade dada a certos temas: os poemas de Ronsard sobre o Vendômois (que se ligariam ao lugar ocupado pelo Valois no imaginário nervaliano) (Nerval, 2011: 108), outros que tratam da miséria da condição humana, da doença e da morte, e que se ligam aos temas da Queda e da perda da Idade de Ouro, ou ainda, de forma mais geral, o tema do tempo que passa, "tópos lyrique que Nerval fera jouer, très consciemment, sur tous les tons (y compris sur le mode de la distanciation ironique) dans les œuvres de maturité" (Nerval, 2011: 113). Num único poema de Ronsard - "À La Haye" - pode-se perceber uma rapsódia de temas que Nerval desenvolverá posteriormente: o questionamento do alcance da razão ("Vers dorés"), a metempsicose e, ainda, a visão cíclica do tempo (esta presente também em Du Bellay e Baif).

Com as sátiras de Mathurin Régnier Nerval encerra seu Choix trazendo à luz uma língua "élastique et souple", "forte et naturelle, tout à la fois claire e colorée" (Nerval, 2011: $360-361)^{12}$ que ele valorizará em sua produção posterior, pela atenção que dedica à "vieille langue française", à fala popular, às canções, aos patois... (Nerval, 2011: 361). A valorização dessa língua está em consonância com a reflexão nervaliana sobre o realismo tal como se encontra, por exemplo, em Les Nuits d'octobre. Mas a retomada de Régnier se liga, de forma mais geral, a um dos avatares que conhecemos de Nerval, o do escritor "fantaisiste, essayiste et réaliste". Certa "allure narrative" que se poderia "caracterizar como all'improvviso", característica de Régnier, reconhece-se em textos como Angélique (1854) et Les Faux Saulniers (1850), assim como em Régnier se pode reconhecer uma liberdade formal e uma mistura de gêneros (tão caracteristicamente romântica) buscada por Nerval em sua própria produção.

Mathurin Régnier seria então um espelho no qual se pode ver retrospectivamente uma das figuras de Nerval, tal como descrita por ele mesmo - "moi, frivole écrivain, mais

\footnotetext{
12 Victor Hugo, Littérature et philosophie mêlées, citado na "Introdução" dos editores à parte dedicada a Mathurin Régnier, apud Nerval, 2011: pp. 360-61.
} 
non pas écrivain facile" (Nerval, 2011: 361), diverso do poeta que ronsardizava, ou daquele que se vincula diretamente à linhagem sonhada de Du Bartas...

Nerval encerra seu Choix com a poesia de Mathurin Régnier e com a mistura de gêneros e a variedade registros que a caracteriza. A palavra "variedade" serve para comentar o livro como um todo. É surpreendente perceber a proximidade de Nerval com poetas do século XVI que, a despeito das muitas similaridades, são bastante diversos uns dos outros. Note-se ainda a variedade dos caminhos pelos quais a obra de Nerval se aproxima de cada um deles (ora pelo tema, ora pelo gênero, ora pela forma, pelo modo de enunciação, pela voz, pela língua...). O próprio vocabulário mobilizado para comentar as similaridades é variado: as semelhanças podem ser vistas pelo prisma da imitação ${ }^{13}$; elas podem ser comentadas por termos ligados à memória: mémoire de la forme, ressouvenirs, réminiscences, échos, résonances; podem ser descritas pela imagem nervaliana do palimpsesto; podem ainda ser vistas como prefigurações ou ser comentadas com recurso a metáforas orgânicas, como féconder, se greffer, ou simplesmente renaître.

Como afirmamos acima, essas metáforas orgânicas de certo modo organizam a "Introdução" de Gérard ao Choix e estão presentes em muitos dos poemas recolhidos por ele. Elas constituem um dos fils rouges por meio de cuja indicação os editores vão alinhavando a discreta unidade presente no trabalho de edição realizado pelo poeta: "la metáphore végétale [...] est probablement le fil conducteur le plus significatif du Choix" (Nerval, 2011: 330). Mas há outros fils rouges, como o tema do tempo que passa, o da perda da Idade de Ouro (Ronsard) e o da figura do poeta (na parte dedicada aos "Discours" de Ronsard, em Du Bellay e em Mathurin Régnier), que seria um "thème essentiel de l'anthologie, où Nerval, conscient de sa vocation interroge cependant, à la lumière de la poésie du $\mathrm{XVI}^{\mathrm{e}}$ siècle, la place et la fonction du poète à l'époque de la bourgeoisie triomphante" (Nerval, 2011: 371).

Esses fils rouges que alinhavam o livro não seriam senão o indício de que os poemas (ou partes de poemas) selecionados se ligam pelo fato de que o poeta Nerval os escolheu. Por esta razão se pode usar uma lente nervaliana (análoga à lente kafkiana de Borges) para lê-los. Mirando a lente pelo outro lado, o que se vê através dessa variedade, de todas essas imagens especulares, de todas essas figuras de poeta trazidas à vida da leitura e projetadas pelo poeta, são facetas pouco contempladas de Nerval. O que se vê é, operando na prática da leitura e da escrita, o princípio que o próprio poeta formulou para a criação literária - "Inventer au fond c'est se ressouvenir" - e o quanto sua mémoire fertile é fecundada pela recordação de leituras. O que se vê, enfim, é um Gérard de Nerval mais

\footnotetext{
${ }^{13}$ De resto, como aponta Emmanuel Buron em sua "Introdução", intitulada "Le travail de l'anthologie": "la relation d'emprunt, appropriation [...] est au cœur de la problématique humaniste de l'imitation" (Nerval, 2011: 28).
} 
rico, mais nuançado, e uma obra nervaliana mais aberta, precisamente por ser considerada naquilo que é uma de suas marcas mais características: o commerce que ela estabelece com poetas de outros tempos e lugares.

A edição de Emmanuel Buron e Jean-Nicolas Illouz "témoigne de la vie des œuvres dans le temps", mas poderíamos também dizer que ela dá testemunho da "Excellence du commerce des muses", título atribuído por Nerval às quatro estrofes que ele seleciona de uma ode de Ronsard, e que têm como tema o don da poesia:

Je suis le trafiqueur des Muses

Et de leur biens maistres du temps

$[\ldots]$

Sans plus, libéral je le donne

À qui me plaist de mes amis.

Reçoy donque ceste largesse,

Et croy que c'est une richesse

Qui par le temps de s'use pas (Nerval, 2011: 143).

Nerval ouviu Ronsard, acolheu o don. Com isto contribuiu para o renascimento dos poetas do XVI em 1830, em sintonia com a ideia de uma poesia universal progressiva. ${ }^{14}$

Contrariando as aparências, o Choix de Gérard pode ser lido como uma obra de Nerval. Contrariando as aparências, a edição do Choix pode ser lida como um ensaio crítico sobre Nerval, ensaio ao qual se aplicariam, a nosso ver, as seguintes palavras de Jean Starobinski a respeito da interpretação da obra literária:

Je dois la faire revivre pour l'aimer, je dois la faire parler pour lui répondre. C'est pourquoi l'on peut dire que l'œuvre commence toujours par être notre 'chère disparue' et que l'elle attend de nous sa réssurrection, ou du moins son évocation la plus intense [...] Hermès, conducteur des âmes et patron de l'herméneutique est celui qui franchit les limites entre les mondes, et qui rend à la présence ce qui avait été englouti par l'absence ou par l'oubli (Starobinski, 1970: 28-29).

\footnotetext{
${ }^{14}$ A "Introdução" de Nerval ao Choix, assim como todo o trabalho de compilação por ele realizado se orientaria para uma literatura por vir e, neste sentido, estaria em conformidade com a visão schlegeliana da crítica, de "uma crítica que não seria apenas o comentário de uma literatura existente, acabada e sem viço, mas antes o organon de uma literatura a ser produzida, formada e acabada. Um organon da literatura, ou seja, uma crítica que buscaria não apenas explicar e conservar, mas que seria ela mesma produtora, ainda que de maneira indireta, ao orientar, organizar e estimular" (Schlegel, 2003: 559-60). Ocorre que a leitura crítica de Nerval é também produtora por estar intimamente imbricada, como vimos, em sua própria criação posterior.
} 
Os editores do Choix puderam trazer à presença essa obra até então oculta de Nerval pois souberam interpretar - a fundo e em toda a sua complexidade - elementos essenciais da poética nervaliana: "Somente mostro que compreendi um escritor quando sou capaz de agir dentro de seu espírito, quando sou capaz de, sem estreitar sua individualidade, traduzi-lo e alterá-lo multiplamente" (Novalis, 2001: 55). Assim como Nerval traduziu e alterou multiplamente os poetas do século XVI, os editores, agindo no espírito do poeta, puderam traduzir essas leituras de Nerval e mostrar que elas devem ser lidas como obra de criação. A consequência de ambas as "traduções" - ou de ambas as metamorfoses - é uma transgressão de fronteiras no domínio literário, um ultrapassar dos limites entre leitura e invenção, criação e crítica que ecoa hoje - na reedição de uma antologia dos poetas do século XVI - formulações do Romantismo alemão que certamente não passaram despercebidas a Nerval, sempre atento ao que ocorria do outro lado do Reno, na Alemanha romântica:

A poesia romântica é uma poesia universal progressiva. Sua destinação não é apenas reunificar todos os gêneros separados da poesia [...]. Quer e também deve ora mesclar, ora fundir poesia e prosa, genialidade e crítica [...] O gênero poético romântico ainda está em devir; sua verdadeira essência é mesmo a de que só pode vir a ser, jamais ser de maneira perfeita e acabada. Não pode ser esgotado por nenhuma teoria, e apenas uma crítica divinatória poderia ousar pretender caracterizar-Ihe o ideal (Schlegel, 1997: 64).

Uma obra como o Choix de Nerval - que inventa livremente seu próprio modo de ser e transgride fronteiras no campo literário - só poderia mesmo ser comentada e trazida à luz por um modo de exposição, ele mesmo, criativo: uma edição crítica que é também um ensaio interpretativo, uma leitura que adivinha e descobre uma obra; em suma, uma leitura feita com arte, para retomarmos uma última vez as palavras de Friedrich Schlegel: "A leitura feita com arte consiste em ler com os outros, em buscar ler, igualmente, a leitura dos outros" (Schlegel, 1996: 258).

\section{Bibliografia}

BORGES, Jorge Luis (2007a). Ficções. São Paulo: Companhia das Letras. Tradução de Davi Arrigucci Jr.

(2007b). Outras Inquisições. São Paulo: Companhia das Letras. Tradução de

Davi Arrigucci Jr. 
CURTIUS, Ernst Robert (1984). "Goethe als Kritiker" ["Goethe como crítico"]. In: Kritische Essays zur europäischen Literatur. Berna: Francke Verlag, pp. 31-56.

NeRVAL, Gérard de (1989). CEuvres complètes. Sob a direção de Jean Guillaume e Claude Pichois. Paris, Gallimard ("Bibliothèque de la Pléiade"), (Tomo I).

(1993). CEuvres complètes. Sob a direção de Jean Guillaume e Claude Pichois. Paris, Gallimard ("Bibliothèque de la Pléiade"), Tomo III. (2011). CEuvres complètes (sob a direção de Jean-Nicolas Illouz).Tomo I: Choix des poésies de Ronsard, Du Bellay, Baïf, Belleau, Du Bartas, Chassignet, Desportes, Régnier. Edição de Emmanuel Buron et Jean-Nicolas Illouz. Paris: Classiques Garnier.

NovalıS (Friedrich von Hardenberg) (2001). Pólen. Tradução, apresentação e notas de Rubens Rodrigues Torres Filho. São Paulo: Editora lluminuras.

SCHLEGEL, Friedrich (1997). O Dialeto dos fragmentos. Tradução, apresentação e notas de Márcio Suzuki. São Paulo: Editora lluminuras.

(1996). “Sur la littérature (1800). Fragment 669 (2016)”. In: Denis Thouard, (org.). Critique et herméneutique dans le premier Romantisme Allemand. Textes de F. Schlegel, F. Schleiermacher, F. Ast, A.W. Schlegel, A.F. Berhardi, W. Dilthey. Paris: Presses Universitaires du Septentrion, p. 258. (2003). "De l'esprit combinatoire”. In: Charles Le Blanc, Laurent Margantin, Olivier Schefer (orgs.). La forme poétique du monde. Anthologie du Romantisme Allemand. Paris: José Corti, pp. 559-563. 